\title{
Population Characteristics and Their Implications on the Benefit Basket of National Social Health Insurance Scheme in Sierra Leone: A Prospective View
}

\author{
Abraham Isiaka Jimmy, ${ }^{1}$ Kwabena Anarfi Boateng, ${ }^{2}$ Peter Twum ${ }^{D},{ }^{2}$ Deborah Larbie, ${ }^{2}$ \\ Abdul Bangura, ${ }^{3}$ Hassan Milton Conteh, ${ }^{4}$ and Peter Agyei-Baffour $\mathbb{C}^{2}$ \\ ${ }^{1}$ University of Makeni, Makeni, Sierra Leone \\ ${ }^{2}$ Department of Health Policy Management and Economics, School of Public Health, College of Health Sciences, \\ Kwame Nkrumah University of Science and Technology (KNUST), Kumasi, Ghana \\ ${ }^{3}$ Médecins Sans Frontières (MSF), Makeni, Sierra Leone \\ ${ }^{4}$ Sierra Leone Ministry of Health and Sanitation, Makeni, Sierra Leone
}

Correspondence should be addressed to Peter Twum; twumpeter2000@yahoo.com

Received 18 January 2021; Revised 19 February 2021; Accepted 23 February 2021; Published 8 March 2021

Academic Editor: Hamidreza Karimi-Sari

Copyright $\odot 2021$ Abraham Isiaka Jimmy et al. This is an open access article distributed under the Creative Commons Attribution License, which permits unrestricted use, distribution, and reproduction in any medium, provided the original work is properly cited.

\begin{abstract}
Background. The government of Sierra Leone introduced social health insurance (SHI) scheme to provide universal health coverage to people. This study was carried out to assess the population characteristics and their implications on the benefit basket of the proposed national health insurance scheme. Methods. A cross-sectional study design was employed in six selected districts in Sierra Leone. Quantitative data were collected for this study through the use of semistructured questionnaires with a sample of 1,185 respondents. Data were analysed using descriptive and inferential statistics. Statistical analysis was run at $5 \%$ significant level using Stata 14.0 software. Results. The study found that most (83.54\%) of the respondents affirmed that children below 18 years should be excluded from premium payments and as high as $71.65 \%$ also stated that pregnant women should be excluded as well. The majority, $63.69 \%$, of the respondents want lactating mothers to be excluded from premium payments. Also, $79.87 \%$ of respondents wanted mentally challenged persons not to pay premium, while a significant proportion (84.26\%) of respondents further affirmed that the aged (above 70 yrs) should also be excluded from premium payment. Most household heads (89.71\%) preferred the accreditation of public health facilities. Regarding the level at which healthcare services should be covered by the scheme, $61.45 \%$ preferred the primary care services, $89 \%$ mentioned secondary care services, and $98.93 \%$ affirmed the provision of tertiary care under the scheme. As for the type of care that should be covered by the scheme, $98.66 \%$ and $99.73 \%$ affirmed outpatient and inpatient care, respectively. Conclusion. From the findings on population characteristics and their implications on the benefit basket for the proposed nation social health in Sierra Leone, most of the household heads want exemptions from paying premium for a section of the population. This provides a clear insight for policy makers into the formulation of the benefit basket.
\end{abstract}

\section{Background}

A number of low and middle income countries (LMICs) have realised the difficulties associated with how to sustain sufficient financing for healthcare, most especially for the poor [1-3]. In view of this, international policy makers and other stakeholders have been recommending a variety of suitable measures, including, but not limited to, various kinds of health insurance schemes, one of which is social health insurance (SHI) $[4,5]$. This can help to move away from out-of-pocket payments for healthcare at the time of use with prepayment health insurance towards mitigating the financial hardship associated with paying for health services [6].

The World Health Organisation (WHO) passed a resolution in 2005 that social health insurance should be supported as one of the strategies to be used to mobilise 
more resources for healthcare service delivery, for risk pooling, increasing access to healthcare for people who are poor, and for delivering quality healthcare especially in low income countries [7]. Health insurance is considered a medium to share the financial risk associated with different kinds of individuals' healthcare costs by pooling the costs over time through the use of prepayment $[8,9]$. Whenever general healthcare coverage is to be funded through insurance, the risk pool needs to portray certain characteristics; (i) contributions to the risk pool should be involuntary so as to thwart the rich and healthy from opting out; (ii) the risk pool should have great numbers of people, as pools with few numbers cannot broaden the risk satisfactorily and are too small to handle large healthcare costs; and (iii) where the majority of the members are poor, pooled funds will generally be subsidised from government revenue $[6,10]$.

It is important at this point to determine the health benefit basket. Thus, the policy should clarify "services, procedures, activities, and goods" that are publicly covered in a specific country. The benefit basket entails three main indicators: breadth, depth, and height. The breadth signifies the populations that are covered, whereas the depth indicates the resources provided, and the height explains the scope of the costs of the services covered. All services, procedures, activities, and equipment that are not covered (i.e., entailing a $100 \%$ copayment) are considered not to be part of the benefit basket or package. Worldwide, the health benefit catalogue is broadly divided into hospital inpatient care, pharmaceuticals, primary care (including outpatient, general, and specialised care), and others (preventive services, allied professional care). Among these broad areas, different methods are used to state the specific catalogues of the package $[8,11]$

Sierra Leone is estimated to have the world's highest maternal mortality ratio. Anaemia is a serious public health problem among pregnant women (70\%) [12]. This could be explained partly by poor access to healthcare services at the time of giving birth and also that the majority of Sierra Leone's population pay user fees to access healthcare [13]. To address financial inaccessibility, the Free Healthcare Initiative was introduced in 2010 to abolish user fees for all pregnant and lactating women and under-five children [14]. Furthermore, Ministry of Health and Sanitation started the implementation of the newly developed National Health Sector Strategic Plan 2017-2021. Again, government launched the Sierra Leone Social Health Insurance (SLeSHI) in 2018 to improve financial accessibility to healthcare [15]. This study was carried out to assess the characteristics of the population and their implications for the benefit basket of the proposed national health insurance scheme in the country.

\section{Methods}

2.1. Study Design. This study is a cross-sectional study by design and analytical by type. It covered the household population in six selected districts in Sierra Leone: Kono $(505,491)$, Bo $(574,026)$, Koinadugu $(408,687)$, Bombali $(605,741)$, Western Area Urban $(1,050,711)$, and Western
Area Rural $(443,068)$. A total household population of $3,587,724$ was used as a target population. The sample size was estimated from the study population using Sample Size Calculator version 2.0.2 by Relief Applications (https://play. google.com $>$ store $>$ apps $>$ details $>\mathrm{id}=$ calculate.sample. size). In this study we used $95 \%$ confidence level and a precision rate of 0.03 to arrive at a sample size of 1,185 households from the total household population $(3,587,724)$.

2.2. Sampling Procedure. A simple random technique was used to select the respondents. This was to ensure that every individual had an equal chance of being selected. A systematic sampling was used to select houses. Every third house was selected, and household heads who fell within the target group were identified and interviewed. Where there was more than one eligible respondent in a house, only one of them was randomly selected, through balloting, to participate in the study. On the other hand, where there was no eligible respondent, interviewers moved to the next house. This process continued until the required number was reached.

2.3. Data Analysis. Data for this study was obtained from a household head through the use of semistructured questionnaire after it was pretested. We used Stata version 14.0 to analyse the data obtained from the study. Both inferential and descriptive analysis were done at 5\% significance level.

\section{Results}

3.1. Sociodemographic Characteristics of Respondents. The sociodemographic characteristics of respondents which involve district of household, head, location, age, gender, marital status, religion, occupation, monthly income, and educational qualification are presented in Table 1 . From the findings, the majority $(29.28 \%)$ of household heads were from Western Area Urban district. In terms of location of household heads in the district, more than half (69.28\%) were from urban areas. The study revealed that the majority (43.63\%) of household heads are within the age bracket of 30-39 years and had attained tertiary education (39.92\%). Most (67.76) of the respondents were males. Vast majority of the respondents (72.24\%) were married. A little over half (52.66\%) of the respondents were Christians. Regarding occupation, a little over two-thirds (62.95\%) were informal workers. As for household heads' monthly income (mean$=$ Le $1,069,945 ; \mathrm{SD}=$ Le $1,307,152)$, about 4 in 10 (37.47\%) were earning less than Le 500,000.

3.2. Population Characteristics and Their Implications on Benefit Basket. In this section, the population characteristics (qualities and characterization of the people based on demography, health status, socioeconomic factors, willingness, and ability to pay for a health-related programme) were assessed in order to be able to formulate appropriate benefit basket for the proposed national health insurance scheme in Sierra Leone, Table 2. 
TABLE 1: Sociodemographic characteristics of household heads.

\begin{tabular}{|c|c|c|c|c|}
\hline Variables & Frequency $(n=1,185)$ & & Percentage & \\
\hline \multicolumn{5}{|l|}{ District of household heads } \\
\hline Kono & 167 & & 14.09 & \\
\hline Bo & 190 & & 16.03 & \\
\hline Bombali & 200 & & 16.88 & \\
\hline Koinadugu & 135 & & 11.39 & \\
\hline Western Area Urban & 347 & & 29.28 & \\
\hline Western Area Rural & 146 & & 12.32 & \\
\hline \multicolumn{5}{|l|}{ Location of household heads } \\
\hline Rural area & 364 & & 30.72 & \\
\hline Urban area & 821 & & 69.28 & \\
\hline \multicolumn{5}{|l|}{ Age in years (categories of household heads) } \\
\hline $20-29$ & 105 & & 8.86 & \\
\hline $30-39$ & 517 & & 43.63 & \\
\hline $40-49$ & 354 & & 29.87 & \\
\hline $50-59$ & 177 & & 14.94 & \\
\hline $60+$ & 32 & & 2.7 & \\
\hline Female & 382 & & 32.24 & \\
\hline Male & 803 & & 67.76 & \\
\hline \multicolumn{5}{|l|}{ Marital status of household heads } \\
\hline Single & 161 & & 13.59 & \\
\hline Married & 856 & & 72.24 & \\
\hline Divorced & 101 & & 8.52 & \\
\hline Widowed & 67 & & 5.65 & \\
\hline \multicolumn{5}{|l|}{ The religion of household heads } \\
\hline Islam & 561 & & 47.34 & \\
\hline Christianity & 624 & & 52.66 & \\
\hline \multicolumn{5}{|l|}{ Occupation of household heads } \\
\hline Informal & 746 & & 62.95 & \\
\hline Formal & 439 & & 37.05 & \\
\hline Categories of household head monthly income & - & - & Mean & SD \\
\hline$<$ Le 500,000 & 444 & 37.47 & & \\
\hline Le $500,000-1,000,000$ & 418 & 35.27 & $1,069,945$ & $1,307,152$ \\
\hline$>$ Le $1,000,000$ & 323 & 27.26 & & \\
\hline \multicolumn{5}{|l|}{ Educational qualification of household heads } \\
\hline No formal education & 306 & & 25.82 & \\
\hline Primary school education & 158 & & 13.33 & \\
\hline Secondary school education & 248 & & 20.93 & \\
\hline Tertiary education & 473 & & 39.92 & \\
\hline
\end{tabular}

Regarding sources of healthcare, slightly above half of respondents (51.05\%) go to a chemist shop as a first step when a member is sick. A vast majority (94.09\%) of the respondents used public health facilities. Out-of-pocket payments accounted for the largest (92.57\%) source of funding health. The data pointed out insufficient funds as the biggest challenge (70.89\%). The majority (76.29\%) were not aware of the proposed SLeSHI. A vast majority (94\%) of the respondents were willing to join and pay the premium.

The mean insurance premium was Le 14,089.45 (SD = Le $18,690.41)$, and less than half $(44.99 \%)$ were willing to contribute Le 10,000-19,000. The majority (51.97\%) who were willing to make monthly contributions belonged to the formal sector. With respect to the preferred mode of premium payment by household heads, $79.52 \%$ preferred monthly payment whereas less than $1 \%$ (0.09\%) preferred paying the premium once in a lifetime. About two-thirds $(60.91 \%)$ of the respondents were willing to accept any form of cost sharing, while the rest (39.09\%) were not. Among those that were willing to accept any form of cost sharing, a little over half (54.33\%) preferred coinsurance. Respondents were further asked if they had confidence in the government for the sustainability of the insurance scheme. Less than a fifth, $13.77 \%$, of respondents indicated that they were not confident.

\subsection{Relationship between Sociodemographic Characteristics} and Willingness to Join the Proposed Health Insurance. Chi-square test was run to assess the relationship between sociodemographic characteristics and willingness to join the proposed health insurance, Table 3 . There was a statistically significant relationship between the willingness to join the proposed SLeSHI and the district in which the individual stays, marital status, religion, occupation, monthly income, educational qualification, and awareness of SLeSHI implementation. 
TABLE 2: Population characteristics and their implications on benefit basket.

\begin{tabular}{|c|c|c|c|c|}
\hline \multirow{2}{*}{$\begin{array}{l}\text { Variables } \\
\text { The first step taken by a household when a member is sick }\end{array}$} & \multicolumn{2}{|l|}{ Frequency $(n=1,185)$} & \multicolumn{2}{|l|}{ Percentage } \\
\hline & & & & \\
\hline Do nothing & 31 & & 2.62 & \\
\hline Go to a chemist shop & 605 & & 51.05 & \\
\hline Go to a prayer camp & 23 & & 1.94 & \\
\hline Use leftover drugs at home & 372 & & 31.39 & \\
\hline Others & 154 & & 13 & \\
\hline \multicolumn{5}{|c|}{ Type of health facility used by household heads in seeking healthcare (multiple choice responses) } \\
\hline \multicolumn{5}{|c|}{ Public facility } \\
\hline No & 70 & & 5.91 & \\
\hline Yes & 1,115 & & 94.09 & \\
\hline \multicolumn{5}{|l|}{ Private facility } \\
\hline No & 910 & & 76.79 & \\
\hline Yes & 275 & & 23.21 & \\
\hline \multicolumn{5}{|l|}{ Mission facility } \\
\hline No & 1,104 & & 93.16 & \\
\hline Yes & 81 & & 6.84 & \\
\hline \multicolumn{5}{|l|}{ Traditional healers } \\
\hline No & 1,032 & & 87.09 & \\
\hline Yes & 153 & & 12.91 & \\
\hline \multicolumn{5}{|l|}{ Chemist shop } \\
\hline No & 800 & & 67.51 & \\
\hline Yes & 385 & & 32.49 & \\
\hline \multicolumn{5}{|l|}{ Funding sources for health-related expenditure } \\
\hline Out of pocket & 1,097 & & 92.57 & \\
\hline Private insurance & 34 & & 2.87 & \\
\hline Social support & 54 & & 4.56 & \\
\hline \multicolumn{5}{|l|}{ Challenges with funding sources } \\
\hline Delay & 333 & & 28.1 & \\
\hline Insufficient fund & 840 & & 70.89 & \\
\hline Abuse & 12 & & 1.01 & \\
\hline \multicolumn{5}{|l|}{ Awareness of SLeSHI implementation } \\
\hline No & 904 & & 76.29 & \\
\hline Yes & 281 & & 23.71 & \\
\hline \multicolumn{5}{|l|}{ Willingness to pay and join the SLeSHI by household heads } \\
\hline No & 67 & & 5.65 & \\
\hline Yes & 1,118 & & 94.35 & \\
\hline Amount willing to contribute in categories in Leones (Le) & Freq. $(n=1,118)$ & $(\%)$ & Mean & SD \\
\hline $1000-9000$ & 338 & 30.23 & & \\
\hline $10000-19000$ & 503 & 44.99 & & \\
\hline $20000-29000$ & 161 & 14.4 & 14089.45 & 18690.41 \\
\hline $30000-39000$ & 49 & 4.38 & & \\
\hline $40000+$ & 67 & 5.99 & & \\
\hline \multicolumn{5}{|l|}{ Willingness to contribute percentage of monthly income } \\
\hline No & 537 & & 48.03 & \\
\hline Yes & 581 & & 51.97 & \\
\hline Total & 1,118 & & 100 & \\
\hline Percent of monthly income formal workers are willing to contribute $(n=581)$ & - & - & Mean & SD \\
\hline $1 \%$ & 136 & 23.41 & & \\
\hline $2 \%$ & 165 & 28.40 & & \\
\hline $3 \%$ & 61 & 10.50 & & \\
\hline $4 \%$ & 29 & 4.99 & 3.03 & 1.80 \\
\hline $5 \%$ & 178 & 30.64 & & \\
\hline $8 \%$ & 7 & 1.20 & & \\
\hline $10 \%$ & 5 & 0.86 & & \\
\hline \multicolumn{5}{|l|}{ Preferred mode of premium payment $(n=1,118)$} \\
\hline Monthly & 889 & & 79.52 & \\
\hline Every six months & 182 & & 16.28 & \\
\hline Yearly & 46 & & 4.11 & \\
\hline
\end{tabular}


TABle 2: Continued.

\begin{tabular}{|c|c|c|}
\hline Variables & Frequency $(n=1,185)$ & Percentage \\
\hline Once in a lifetime & 1 & 0.09 \\
\hline \multicolumn{3}{|c|}{ Willingness to accept any form of cost sharing $(n=1,118)$} \\
\hline No & 437 & 39.09 \\
\hline Yes & 681 & 60.91 \\
\hline \multicolumn{3}{|c|}{ The preferred form of cost sharing (multiple choice responses) $n=681$} \\
\hline \multicolumn{3}{|c|}{ Coinsurance } \\
\hline No & 311 & 45.67 \\
\hline Yes & 370 & 54.33 \\
\hline \multicolumn{3}{|l|}{ Copayment } \\
\hline No & 358 & 52.57 \\
\hline Yes & 323 & 47.43 \\
\hline \multicolumn{3}{|l|}{ Deductible } \\
\hline No & 318 & 46.7 \\
\hline Yes & 363 & 53.3 \\
\hline \multicolumn{3}{|c|}{ Level of confident of household heads $(n=1,118)$} \\
\hline Not confident & 154 & 13.77 \\
\hline Somehow confident & 386 & 34.53 \\
\hline Confident & 295 & 26.39 \\
\hline Very confident & 158 & 14.13 \\
\hline Highly confident & 125 & 11.18 \\
\hline
\end{tabular}

*indicate significant association between the variable and willingness to pay.

TABLE 3: Chi-square test of independent relationship.

\begin{tabular}{|c|c|c|c|c|}
\hline \multirow{2}{*}{ Variables } & \multirow{2}{*}{ Frequency } & \multicolumn{2}{|c|}{ Willingness to pay } & \multirow{2}{*}{ Chi-square test } \\
\hline & & No (\%) & Yes (\%) & \\
\hline \multicolumn{5}{|l|}{ District of respondents } \\
\hline Kono & 167 & 0 & 14.09 & \multirow{6}{*}{$0.01^{*}$} \\
\hline Bo & 190 & 0.17 & 15.86 & \\
\hline Bombali & 200 & 1.01 & 15.86 & \\
\hline Koinadugu & 135 & 3.71 & 7.68 & \\
\hline Western Area Urban & 347 & 0.51 & 28.78 & \\
\hline Western Area Rural & 146 & 0.25 & 12.08 & \\
\hline \multicolumn{5}{|l|}{ Location of household } \\
\hline Rural area & 364 & 1.33 & 29.37 & \multirow{2}{*}{0.21} \\
\hline Urban area & 821 & 4.3 & 64.98 & \\
\hline \multicolumn{5}{|c|}{ Age of respondent in years } \\
\hline $20-29$ & 105 & 0.42 & 8.44 & \multirow{5}{*}{0.42} \\
\hline $30-39$ & 517 & 2.7 & 40.93 & \\
\hline $40-49$ & 354 & 1.52 & 28.35 & \\
\hline $50-59$ & 177 & 0.68 & 14.26 & \\
\hline $60+$ & 32 & 0.34 & 2.36 & \\
\hline \multicolumn{5}{|l|}{ Sex of respondents } \\
\hline Female & 803 & 1.35 & 30.89 & \multirow{2}{*}{0.13} \\
\hline Male & 161 & 4.3 & 63.46 & \\
\hline \multicolumn{5}{|l|}{ Marital status } \\
\hline Single & 853 & 0.93 & 12.66 & \multirow{4}{*}{$0.01^{*}$} \\
\hline Married & 101 & 3.71 & 68.52 & \\
\hline Divorced & 67 & 0.08 & 8.44 & \\
\hline Widowed & 561 & 0.93 & 4.73 & \\
\hline \multicolumn{5}{|l|}{ Religion } \\
\hline Islam & 624 & 4.3 & 43.04 & \multirow{2}{*}{$0.01^{*}$} \\
\hline Christianity & 746 & 1.35 & 51.31 & \\
\hline \multicolumn{5}{|c|}{ Occupation of household heads } \\
\hline Informal worker & 439 & 4.22 & 58.73 & \multirow{2}{*}{$0.04^{*}$} \\
\hline Formal worker & 444 & 1.43 & 35.61 & \\
\hline Monthly income of hou & & & & \\
\hline
\end{tabular}


TABle 3: Continued.

\begin{tabular}{|c|c|c|c|c|}
\hline \multirow{2}{*}{ Variables } & \multirow{2}{*}{ Frequency } & \multicolumn{2}{|c|}{ Willingness to pay } & \multirow{2}{*}{ Chi-square test } \\
\hline & & No $(\%)$ & Yes (\%) & \\
\hline$<$ Le 500,000 & 418 & 2.53 & 34.94 & \multirow{3}{*}{$0.01^{*}$} \\
\hline Le $500,000-1,000,000$ & 323 & 2.78 & 32.49 & \\
\hline$>$ Le $1,000,000$ & 306 & 0.34 & 26.92 & \\
\hline \multicolumn{5}{|l|}{ Educational qualification } \\
\hline Nonformal education & 158 & 1.77 & 24.05 & \multirow{4}{*}{$0.02^{*}$} \\
\hline Primary school education & 248 & 0.33 & 13 & \\
\hline Secondary school education & 473 & 1.86 & 19.07 & \\
\hline Tertiary education & 904 & 1.69 & 38.23 & \\
\hline \multicolumn{5}{|c|}{ Awareness of SLeSHI implementation } \\
\hline No & 904 & 5.4 & 70.89 & \multirow{2}{*}{$0.01^{*}$} \\
\hline Yes & 281 & 0.25 & 23.46 & \\
\hline \multirow{2}{*}{ Variables } & \multirow{2}{*}{ Total (\%) } & \multicolumn{2}{|c|}{ Willingness to join } & \multirow{2}{*}{ Chi-square test } \\
\hline & & No $(\%)$ & Yes $(\%)$ & \\
\hline \multicolumn{5}{|l|}{ District of respondents } \\
\hline Kono & 14.09 & 0 & 14.09 & \multirow{6}{*}{$0.01^{*}$} \\
\hline Bo & 16.03 & 0.17 & 15.86 & \\
\hline Bombali & 16.88 & 1.01 & 15.86 & \\
\hline Koinadugu & 11.39 & 3.71 & 7.68 & \\
\hline Western Area Urban & 29.28 & 0.51 & 28.78 & \\
\hline Western Area Rural & 12.33 & 0.25 & 12.08 & \\
\hline \multicolumn{5}{|l|}{ Location of household } \\
\hline Rural area & 30.72 & 1.33 & 29.37 & \multirow[b]{2}{*}{0.21} \\
\hline Urban area & 69.28 & 4.3 & 64.98 & \\
\hline Age of respondent in years & & & & \\
\hline $20-29$ & 8.86 & 0.42 & 8.44 & \\
\hline $30-39$ & 43.63 & 2.7 & 40.93 & \\
\hline $40-49$ & 29.87 & 1.52 & 28.35 & 0.42 \\
\hline $50-59$ & 14.94 & 0.68 & 14.26 & \\
\hline $60+$ & 2.7 & 0.34 & 2.36 & \\
\hline Sex of respondents & & & & \\
\hline Female & 32.24 & 1.35 & 30.89 & 013 \\
\hline Male & 67.76 & 4.3 & 63.46 & 0.13 \\
\hline Marital status & & & & \\
\hline Single & 13.59 & 0.93 & 12.66 & \\
\hline Married & 72.24 & 3.71 & 68.52 & \\
\hline Divorced & 8.52 & 0.08 & 8.44 & $0.01^{*}$ \\
\hline Widowed & 5.65 & 0.93 & 4.73 & \\
\hline Religion & & & & \\
\hline Islam & 47.34 & 4.3 & 43.04 & \\
\hline Christianity & 52.66 & 1.35 & 51.31 & $0.01^{*}$ \\
\hline Occupation of household head & & & & \\
\hline Informal worker & 62.95 & 4.22 & 58.73 & \\
\hline Formal worker & 37.05 & 1.43 & 35.61 & $\mathbf{0 . 0 4}^{*}$ \\
\hline Monthly income of household & & & & \\
\hline$<$ Le 500,000 & 37.47 & 2.53 & 34.94 & \\
\hline Le $500,000-1,000,000$ & 35.27 & 2.78 & 32.49 & $0.01^{*}$ \\
\hline$>$ Le $1,000,000$ & 27.26 & 0.34 & 26.92 & \\
\hline Educational qualification & & & & \\
\hline Nonformal education & 25.82 & 1.77 & 24.05 & \\
\hline Primary school education & 13.33 & 0.33 & 13 & \\
\hline Secondary school education & 20.93 & 1.86 & 19.07 & $0.02^{2}$ \\
\hline Tertiary education & 39.92 & 1.69 & 38.23 & \\
\hline Awareness of SLeSHI impleme & & & & \\
\hline No & 76.29 & 5.4 & 70.89 & \\
\hline Yes & 23.71 & 0.25 & 23.46 & $0.01^{*}$ \\
\hline
\end{tabular}


3.4. Preferred Choices for Benefit Basket. Benefit basket includes all services, procedures, activities, and goods covered by public funding in a given country. Any of these that are not covered are not considered part of the benefit basket. This study assumed that to formulate an adequate benefit basket and to have an acceptable level of participation by clients, the characteristics of the population of a country need to be assessed for their preferred choices about the content and scope of the benefit basket for the implementation of SLeSHI (Table 4).

From Table 4, most (83.54\%) respondents affirmed that children below 18 years should be excluded from premium payments, and as high as $71.65 \%$ also stated that pregnant women should be excluded as well. The majority, $63.69 \%$, of the respondents were of the view that lactating mothers should be excluded from premium payments. In addition, $79.87 \%$ of respondents stated that mentally challenged persons should not pay premium while a significant proportion $(84.26 \%)$ of respondents further affirmed that the aged (above 70 yrs) should also be excluded from premium payment.

Most household heads (89.71\%) preferred the accreditation of public health facilities. Regarding the level at which healthcare services should be covered by the scheme, $61.45 \%$ preferred the primary care services, $89 \%$ mentioned secondary care services, and $98.93 \%$ affirmed the provision of tertiary care under the scheme. In respect of the type of care that should be covered by the scheme, $98.66 \%$ and $99.73 \%$ affirmed outpatient and inpatient care, respectively.

\section{Discussion}

The findings from the study showed that the majority of the household heads go to the chemist shop as a first step taken whenever a member is sick. This may be attributed to the closeness as well as the informal relations households have with chemical shop operators. Moreover, the attitude of healthcare providers, affordability, and proximity to healthcare services at the facility level may be contributing to this decision of household heads [16]. In the case of those who seek care at the hospital, they prefer public health facilities. The reason may be that public facilities are more accessible compared to other types of facilities. From the study, out-of-pocket payment accounted for the highest source of funding for health-related expenditure which is in line with an earlier study [10], and the implication is that it may lead to a huge financial burden on or catastrophic spending for the people.

In this study, we found that the majority of respondents were not aware of the implementation of the proposed SLeSHI. This could be explained by the fact that the government has not developed much awareness about the scheme. This is in contrast to the findings of [17], who found that more than half of the public servants in Juba City are aware of NHIF. On the other hand, in Nigeria, [18] found that less than half of the participants were aware of community-based health insurance schemes (CBHIS), which corroborates the findings of this study.
TABLe 4: Preferred choices for benefit basket.

\begin{tabular}{|c|c|c|}
\hline Variables & Frequency $(n=1,118)$ & Percentage \\
\hline \multicolumn{3}{|c|}{$\begin{array}{l}\text { Preferred categories of exclusion by household heads from } \\
\text { premium payment (multiple responses) }\end{array}$} \\
\hline \multicolumn{3}{|c|}{ Children below 18 years } \\
\hline No & 184 & 16.46 \\
\hline Yes & 934 & 83.54 \\
\hline \multicolumn{3}{|c|}{ Men and women above } \\
\hline \multicolumn{3}{|c|}{18 years } \\
\hline No & 1,064 & 95.17 \\
\hline Yes & 54 & 4.83 \\
\hline \multicolumn{3}{|c|}{ Pregnant women } \\
\hline No & 317 & 28.35 \\
\hline Yes & 801 & 71.65 \\
\hline \multicolumn{3}{|c|}{ Lactating mothers } \\
\hline No & 406 & 36.31 \\
\hline Yes & 712 & 63.69 \\
\hline \multicolumn{3}{|c|}{ Mentally challenged person } \\
\hline No & 225 & 20.13 \\
\hline Yes & 893 & 79.87 \\
\hline \multicolumn{3}{|l|}{ Aged } \\
\hline No & 176 & 15.74 \\
\hline Yes & 942 & 84.26 \\
\hline
\end{tabular}

Preferred service providers/facility by household heads that should be accredited (multiple responses)

\begin{tabular}{|c|c|c|}
\hline \multicolumn{3}{|c|}{ Public providers/facilities } \\
\hline No & 115 & 10.29 \\
\hline Yes & 1,003 & 89.71 \\
\hline \multicolumn{3}{|c|}{ Private providers/facilities } \\
\hline No & 568 & 50.81 \\
\hline Yes & 550 & 49.19 \\
\hline \multicolumn{3}{|c|}{ Mission providers/facilities } \\
\hline No & 563 & 50.36 \\
\hline Yes & 555 & 49.64 \\
\hline \multicolumn{3}{|c|}{$\begin{array}{l}\text { Preferred healthcare services by household heads that should be } \\
\text { covered (multiple responses) }\end{array}$} \\
\hline \multicolumn{3}{|c|}{ Primary care } \\
\hline No & 431 & 38.55 \\
\hline Yes & 687 & 61.45 \\
\hline \multicolumn{3}{|c|}{ Secondary care } \\
\hline No & 123 & 11 \\
\hline Yes & 995 & 89 \\
\hline \multicolumn{3}{|c|}{ Tertiary care } \\
\hline No & 12 & 1.07 \\
\hline Yes & 1,106 & 98.93 \\
\hline \multicolumn{3}{|c|}{ Covering of outpatient care } \\
\hline No & 15 & 1.34 \\
\hline Yes & 1,103 & 98.66 \\
\hline \multicolumn{3}{|c|}{ Covering of inpatient care } \\
\hline No & 3 & 0.27 \\
\hline Yes & 1,115 & 99.73 \\
\hline
\end{tabular}

Furthermore, it was found that majority of household heads were willing to join the scheme and pay the premium with a few disagreeing. The reason for willingness to join was that they would benefit from the scheme as the government would take care of their high health-related expenditure and help their family members to access healthcare by reducing their direct out-of-pocket payment; they also believed that it would be helpful to them in times of emergency when 
money may not be readily available in seeking healthcare due to the uncertainty of disease occurrence. Those who said they were not willing to join the scheme perceived that the premium contributions might be high as they have other family responsibilities to address. Some respondents also stated a lack of trust and confidence in the government for the sustainability of the program and believed that corruption could collapse the scheme.

A significant number of household heads were willing to contribute a mean of Le 14,089.45, 95\% CI (12992.67-15186.22), as premium. This may be attributed to the fact that the majority of the household heads were educated and therefore knew the importance of subscribing to the health insurance schemes. This study further reveals that more than half of the formal workers are willing to contribute to the proposed scheme. This may be explained by the fact that most of them are educated and therefore know the benefits associated with subscribing to health insurance. These findings are in line with earlier studies which identified education, income, and age as factors that influence people's willingness to subscribe and pay for health insurance. A study conducted by [17] in South Sudan among public servants in Juba City reveals that willingness to pay is primarily affected by education. Moreover, [10] found that, among civil servants in the city of Mekelle, the northern part of Ethiopia, willingness to pay has been correlated significantly with age, educational level, and household income.

However, the amount of money respondents said they would like to pay as premium is inconsistent with the proposed $4 \%$ premium contribution from formal workers as per the proposed national health insurance scheme in Uganda and Arusha (2014) as cited by [17]. This may imply that the residents in Sierra Leone are not willing to pay any amount that is beyond the said mean contributions, especially the informal workers. Moreover, it implies that the funds that will be available for the scheme when established will be significantly low, except that there are other sources of funding which could be from the central government, corporate bodies, and external sources. With this low level of average amount that clients are willing to pay vis-a-vis the high prevalence of the disease, a comprehensive analysis is warranted for an appropriate and adequate content, scope, and depth of the benefit basket. Using only the willingness to pay may have a dire consequence on the quality of service delivery and sustainability of the scheme.

According to the WHO Universal Health Coverage cube, the formulation of benefit basket depends on three dimensions of coverage: the breadth which refers to the population coverage, the depth (service coverage), and height (cost coverage) In this study, individuals from six selected districts in Sierra Leone, including both formal and informal workers, were examined on their preferences for the benefit basket for the proposed national social health insurance scheme. This study assumes that the preference of the population provides a significant policy input in formulating the benefit basket for the SLeSHI and supports the participation of the populace for higher enrolment to sustain the scheme.
A clear picture of the preference of individuals as to the benefit basket is necessary to estimate the insurance uptake rate and the implementation of a SHI scheme [19]. The study explored who should be in the exemption bracket. A majority of respondents are of the view that children below the age of 18 years, pregnant women, lactating mothers, mentally challenged individuals, and the aged (above 70 years) should be exempted. This exemption list of national health insurance does not conform to the best practice in many health insurance countries like Burkina Faso, Tanzania, Ghana, and Rwanda as majority of the insured are below 18 years and above 70 years. In Ghana, for instance, a study [20] found that about 56 percent of the insured were below 18 years and above 70 years. This may mean that a lot of financial burden may be on the scheme which can affect the quality of care and render the NHIS insolvent.

Moreover, a majority of respondents prefer that the public health facilities should be more accredited compared to private and mission facilities. This is so because public health facilities in Sierra Leone are more than private and mission ones and the cost of care is cheaper for the public than the latter. The results could be due to the fact that this study covered more rural than urban areas which are served by public health facilities.

For service coverage, the study shows that there is a preference for the coverage of all three levels of care (primary, secondary, and tertiary), with tertiary care accounting for the highest preference, followed by secondary and primary care, respectively. They also prefer coverage of both outpatient and inpatient care. The above preference for coverage of services means that the government of Sierra Leone will bear the major burden of the scheme on the grounds that the people are willing to pay less monthly premium. Covering the preferred services may require a substantial fund for the scheme. It means, for the formulation of an attractive benefit basket, that the scheme may require extra financial support outside the household to protect the populace from a catastrophic expenditure. This finding is not surprising as it is in line with a study conducted in Nigeria on the preference for benefit packages for community-based health insurance [21], in which it was also found that people preferred a benefit basket that covers everything including inpatient and outpatient services. It is also similar to the findings in a previous study by Dong et al. (2004), which revealed a strong preference for the covering of high-cost healthcare services.

4.1. Strengths and Limitations. The study was one of the few studies done on the proposed SLeSHI, characterising the population, covering more rural areas, and focusing on the benefit basket for the proposed social health insurance scheme. However, like any cross-sectional study design, it is possible that the results may have been affected by social desirability, sample variability, and recall bias which could have under- or overestimated the income and amount of money the respondents said they are willing to pay as premium. Besides, it did not cover disease preferences of the people that need to be covered. Nevertheless, the study 
upheld the measures to ensure validity and reliability by employing random sampling, pretesting tools, making statistical adjustments such as design effects and nonresponse rates, and subjecting the study protocols to Institutional Review of Board, Office of the Sierra Leone Ethics and Scientific Review Committee, which are consistent with best scientific practice. We strongly believe that these measures reduced the errors to the barest level and would not have any dire effect on the policy utility of the findings.

\section{Conclusions}

Majority of the household heads want children below 18 years, pregnant and lactating mothers, and the aged, 70 yrs and above, as well as the mentally retarded to be excluded from premium payment. This will go a long way to reduce maternal mortality rate as well as increasing the general population access to healthcare.

\section{Abbreviations}

USD: United States dollar

LMIC: Low- and middle-income countries

SHI: Social health insurance

WHO: World Health Organisation

UHC: Universal health coverage.

\section{Data Availability}

Data for this study will be made available upon request.

\section{Ethical Approval}

Ethical approval was sought from the Ethical Review Board of Sierra Leone.

\section{Consent}

A written consent form was issued to respondents to seek their consent to participate in the study. They were assured that their contribution to the study would be confidential and the data provided can only be used for the study. The respondents were also informed that no form of financial incentive will be given to them for being part of the study and that their choice of not being part of the study cannot stop them from getting any benefit that may come as a result of the study.

\section{Conflicts of Interest}

The authors declare no conflicts of interest.

\section{Authors' Contributions}

A. I. J. and P. A.-B. conceived and initiated the study. A. I. J. designed the study, provided training and guidance for data collection and analysis, and further prepared the original draft of the manuscript. P. A.-B. assisted with supervision, editing, and technical support in all areas of the study. A. B. and H. M. C. assisted with the data collection and provided monitoring to the entire team for data collection. The draft manuscript was critically reviewed by P.T. P. A.-B. and A. I. J. are the guarantors. All authors made significant contributions to the final work; read and approved the manuscript for submission; and gave their consent for the manuscript to be published.

\section{Acknowledgments}

This work was funded by the Sierra Leone Academic Mission (SLAM) Committee Canada.

\section{References}

[1] A. Asante, J. Price, A. Hayen, S. Jan, and V. Wiseman, "Equity in health care financing in low- and middle-income countries: a systematic review of evidence from studies using benefit and financing incidence analyses," PLoS One, vol. 11, no. 4, p. e0152866, 2016.

[2] D. McIntyre, Learning from Experience: Health Care Financing in Low-and Middle-Income Countries, Global Forum for Health Research, Geneva, Switzerland, 2007.

[3] D. Chisholm, S. Docrat, J. Abdulmalik et al., "Mental health financing challenges, opportunities and strategies in low- and middle-income countries: findings from the Emerald project," BJPsych Open, vol. 5, no. 5, p. e68, 2019.

[4] A. Acharya, S. Vellakkal, F. Taylor et al., Impact of National Health Insurance for the Poor and the Informal Sector in Lowand Middle-Income Countries: A Systematic Review, EPPI-Centre, Social Science Research Unit, Institute of Education, University of London, London, UK, 2012.

[5] M. Lagarde and N. Palmer, "The impact of health financing strategies on access in low and middle income countries: protocol," Cochrane Database of Systematic Reviews, vol. 2018, no. 4, Article ID CD006092, 2018.

[6] WHO, The World Health Report: Health Systems Financing: The Path to Universal Coverage, World Health Organization, Geneva, Switzerland, 2010.

[7] WHO, "Sustainable health financing, universal coverage, and social health insurance," in 58th World Health Assembly, WHO, Geneva, Switzerland, 16th edition, 2005.

[8] N. Palmer, D. H. Mueller, L. Gilson, A. Mills, and A. Haines, "Health financing to promote access in low income settingshow much do we know?" The Lancet, vol. 364, no. 9442, pp. 1365-1370, 2004.

[9] E. Etiaba, O. Onwujekwe, A. Honda, O. Ibe, B. Uzochukwu, and K. Hanson, "Strategic purchasing for universal health coverage: examining the purchaser-provider relationship within a social health insurance scheme in Nigeria," $B M J$ Global Health, vol. 3, no. 5, p. e000917, 2018.

[10] M. T. Gidey, G. B. Gebretekle, M.-E. Hogan, and T. G. Fenta, "Willingness to pay for social health insurance and its determinants among public servants in Mekelle City, Northern Ethiopia: a mixed methods study," Cost Effectiveness and Resource Allocation, vol. 17, p. 2, 2019.

[11] S. Smith, "The Irish "health basket": a basket case?" The European Journal of Health Economics, vol. 11, no. 3, pp. 343-350, 2010.

[12] B. S. Kandeh, "Causes of infant and early childhood deaths in Sierra Leone," Social Science \& Medicine, vol. 23, no. 3, pp. 297-303, 1986.

[13] I. Edoka, B. McPake, T. Ensor, R. Amara, and J. Edem-Hotah, "Changes in catastrophic health expenditure in post-conflict 
Sierra Leone: an Oaxaca-blinder decomposition analysis," International Journal for Equity in Health, vol. 16, no. 1, p. 166, 2017.

[14] C. Robinson, "Primary health care and family medicine in Sierra Leone," African Journal of Primary Health Care \& Family Medicine, vol. 11, no. 1, pp. e1-e3, 2019.

[15] M. K. Jofre-Bonet and J. Kamara, "Willingness to pay for health insurance in the informal sector of Sierra Leone," PLoS One, vol. 13, no. 5, p. e0189915, 2018.

[16] A. Kuwawenaruwa, K. Wyss, K. Wiedenmayer, E. Metta, and F. Tediosi, "The effects of medicines availability and stock-outs on household's utilization of healthcare services in Dodoma region, Tanzania," Health Policy and Planning, vol. 35, no. 3, pp. 323-333, 2020.

[17] R. A. Basaza, P. K. Alier, P. Kirabira, D. Ogubi, and R. L. L. Lako, "Willingness to pay for national health insurance fund among public servants in Juba City, South Sudan: a contingent evaluation," International Journal for Equity in Health, vol. 16, p. 158, 2017.

[18] A. S. Oyekale, "Factors influencing households' willingness to pay for national health insurance scheme (NHIS) in Osun State, Nigeria," Studies on Ethno-Medicine, vol. 6, no. 3, pp. 167-172, 2012.

[19] A. Glassman, U. Giedion, Y. Sakuma, and P. C. Smith, "Defining a health benefits package: what are the necessary processes?" Health Systems \& Reform, vol. 2, no. 1, pp. 39-50, 2016.

[20] A. M. Kotoh, G. C. Aryeetey, and S. Van der Geest, "Factors that influence enrolment and retention in Ghana' national health insurance scheme," International Journal of Health Policy and Management, vol. 7, no. 5, pp. 443-454, 2018.

[21] O. Onwujekwe, N. Ezumah, C. Mbachu et al., "Exploring effectiveness of different health financing mechanisms in Nigeria; what needs to change and how can it happen?" BMC Health Services Research, vol. 19, no. 1, p. 661, 2019. 